\title{
Afeto, proximidade, frequência e uma clínica hesitante: bases do "vínculo" entre pacientes com síndrome de Down e a Atenção Primária à Saúde?
}

\author{
Affection, proximity, frequency and hesitant clinical practice: \\ basis of the "bond" between Down syndrome patients \\ and primary health care?
}

${ }^{1}$ Departamento de M edicina, Universidade Federal deSão Carlos. Rod. Washington Luís Km 235, CampusdaUFSCar/ Departamento de M edicina (área norte). 13565-905 São Carlos SP. dgmelo@ufscar.br
Abstract The national policy of comprehensive care in clinical genetics propounds that families and individuals with genetic disorders should receive ongoing assistance at primary health care (PHC) level. In this study, the social representation of professionals working in family health care units ( $\mathrm{FHCU}$ ) is investigated based on their "bond" with Down syndrome patients, bearing in mind that this expression currently contains relevant meanings in the clinical practice and service management routine. Sixteen practitioners were interviewed, and the sample was defined by theoretical saturation. The statements given by the participants expressed knowledgebased mainly on affective skills, physical proximity and patients' frequency of attendance at the family health care unit (FHCU). Clinical skills of other kinds, especially cognitive skills, do not appear to justify the notion of "bond." The results indicate the need of continuous professional education and definition of guidelines and approaches in care to the most common syndromes in the context of primary health care $(\mathrm{PHC})$.

Key words Bond, Down syndrome, Primary health care, Professional-patient relations, Social psychology
Resumo A Política Nacional deAtenção Integral em Genética Clínica preconiza que famílias e indivíduos com doenças genéticas sejam acompanhadosna A tenção Primária à Saúde(APS). N este trabalho investigamos as representações sociais de profissionais que trabalham em Unidades de Saúde de Família (USF) sobre o "vínculo" entre eles e os pacientes com síndrome de D own, considerando que esta expressão concentra atualmente significados relevantes no cotidiano clinico e gerencial dos serviços. Dezesseis profissionais foram entrevistados, tendo a amostra sido fechada por saturação teórica. Os enunciados proferidos pel os participantes expressaram saberes baseados sobretudo nas ideias de habilidades afetivas, de proximidade física e de frequência de comparecimento dos pacientes às USF. Habilidades clínicas de outras dimensões, notadamente as cognitivas, não parecem fundamentar a noção de "vínculo". Os resultadossugerem a necessidadede educação profissional continuada ede estabelecimento de dire trizes elinhas de cuidado para as síndromes gené ticas mais comuns no âmbito da APS.

Palavras-chave Vínculo, Síndrome de Down, Atenção primária à saúde, Relações profissionalpaciente, Psicologia social 
Introdução

Em 2009, o M inistério da Saúde brasileiro instituiu a Política Nacional de Atenção Integral em Genética Clínica, preconizando o acompanhamento de indivíduos com doenças geneticamente determinadas eanomalias congênitas na Atenção Básica ou Primária à Saúde (APS) ${ }^{1}$.

Ao utilizar a expressão acompanhar indivíduos e famílias, uma das ideias subjacentes à portaria é que os profissionais das Equipes de Saúde da Família (EqSF) estabeleçam laços de compromisso e de corresponsabilidade com esses usuários. Ou, em outras palavras, que estabeleçam vínculo com eles, utilizando vocábulo presente atualmente no cotidiano dos profissionais da APS, na literatura técnica brasilei ra sobreestenível de atenção à saúde, assim como nos textos ministeriais que explicitam alguns de seus marcos referenciais políticos e teórico-conceituais². $M$ encionado na diretriz conceitual sobre Atenção Básica e Saúde da Família do Departamento deAtenção Básica do M inistério da Saúde³, o termo vínculo referir-se-ia, no nosso entender, a um contrato tácito de prestação de serviços ${ }^{4}$, fator facilitador da estratégia da longitudinalidade do cuidado na APS 5

As mudanças estruturais dos fluxos assistenciais propostas pela Estratégia de Saúde da Família incitam de fato à reflexão sobre as relações interpessoais e institucionais entre os três vértices da interação política e sociocultural em jogo: usuários (pacientes), profissionais e as instituições/serviços.

Especificamente em relação à síndrome de Down (SD), condição relativamente comum, com incidência ao redor de 1:1.000 recém-nascidos ${ }^{6}$, os profissionais da APS deverão, ao se vincularem aos pacientes, estar progressivamente mais aptos e qualificados para acompanhá-los e às suas famílias, atuando na promoção às suas saúdes etambém na identificação e no manejo clínico das possíveis complicações associadas à síndrome. Não parece que é isso que acontece atualmente. Revisão sistemática que envolveu 16 artigos e avaliou o nível de conhecimento e informação recebida por pais de pacientes com SD, mostrou que eles recebem poucas informações, criticam a forma como as informações são dadas e ressaltam o despreparo dos profissionais de saúde em lidar com a família ecom o paciente com SD, o que dificulta a adesão deles ao tratamento dos filhos ${ }^{7}$. Estudos que investigam o acompanhamento de pacientes com SD na APS estão preocupados com a realização de medidas clínicas de preven ção terciária帛12, mas não seocuparam atéo momento de estudar o vínculo entre os pacientes e os profissionais de saúde.

Parece-nos, portanto, bastante atual a temática vinculação entre os pacientes com SD eos profissionais de EqSF. Dessa forma, procuramos empreender uma investigação empírica que sondassea perspectiva dos profissionais dessas Equipes sobre como tais vínculos ocorrem atualmente ou passarão a ocorrer.

Por estarem envolvidos dois termos (síndromede D own evínculo) originados de campos reificados do conhecimento (genéticaclínica edireito), objetivamos contribuir para a decodificação das representaçōes sociais sobre o vínculo que se estabelece entre profissionais das EqSF e as famílias e pacientes com SD. Noutras palavras, decodificar o sistema de signosa partir dos quais ocorre a comunicação dentro dessas Equipes e entre elas ea população usuária dos serviços. $\mathrm{Ou}$, mais especificamente, objetivamos identificar elementosqueajudem a esclarecer como vem sendo feita a apropriação pelos profissionais das EqSF dos termos vínculo e síndrome de Down, identificando os conceitos e as ideias que são comunicados nesta conjuntura e que, portanto, fundamentariam as ações práticas levadas a cabo no contexto em Unidades de Saúde da Família (USF).

Tais objetivos foram formulados com base no texto de $\mathrm{Herzlich}{ }^{13}$ sobre os propósitos a que se destinam os estudos sobre as representações sociais (RS). A diferenciação queM oscovici ${ }^{14}$ propôs entre representação social e o conceito Durkheiniano de representação coletiva quis justamente enfatizar queas representações podem ser descritas e explicadas quanto aos papéis quecumprem na resignificação de conceitos surgidos originalmente fora do universo consensual compartilhado cotidianamente pelas pessoas, sendo que tais significações operariam nas compreensões de suas vidas cotidianas e na comunicação que fazem destas compreensões.

Começamos a presente pesquisa com os se guintes pressupostos:

- o uso do termo vínculo nos atuais textos oficiais originar-se ia das áreas do direito e do marketing, remetendo à noção de vínculo contratual ${ }^{4,15}$;

- o vocábulo vínculo, no entanto, inserir-se ia hoje no dia a dia de trabalho dos profissionais das EqSF sob uma parcial influência de seu sentido denotativo inespecífico e também do conceito psicanalítico associado ao termo $0^{16,17}$.

- quanto à SD, embora seja uma doença ge nética comum epara qual estão estabelecidas me 
didas antecipatórias de cuidado clínico que de vem ser realizadas na APS, a compreensão desta condição pelos profissionais das EqSF seria derivada sobretudo de um fluxo de informações de natureza principalmentenão técnica, não clínica e não científica, em razão sobretudo do fato histórico de que o contexto assistencial de cuidado aos pacientes com SD no Brasil tem sido delegado às Organizações N ão Governamentais ( como as Associações de Pais e Amigos de Excepcionais - APAE) ou aos profissionais de saúde que trabalham na atenção especializada.

- uma efetiva relação de vínculo entre a APS e os pacientes com SD deverá ser fortemente permeada pelo que é específico do setor Saúde: a atenção às necessidades clínicas individuais desses sujeitos, assim como a atenção às necessidades coletivas da população acometida pela síndrome e seus familiares.

\section{M etodologia}

O presente texto corresponde a uma parte dos resultados de uma investigação mais ampla sobre representações sociais sobre SD entre profissionais de EqSF, cuja produção dos dados foi realizada entre os anos de 2008 e 2009. A pesquisa foi aprovada pelo Comitê de Ética em Pesquisa com Seres Humanos da UFSCar e todos os participantes assinaram o Termo de Consentimento Livree Esclarecido.

Os critérios de inclusão dos participantes no estudo foram: ser profissional da saúde, trabaIhar na APS como membro de uma EqSF e já ter tido contato profissional com pessoas com SD. 0 processo de amostragem previu a inclusão de participantes com características sociodemográficas e profissionais diversas, a serem entrevistados até que os dados disponíveis fossem considerados suficientes para 0 alcance dos objetivos inicialmente formulados. A amostra terminou sendo composta por 16 profissionais de saúde de diferentes níveis de escolaridade e formações, que trabalhavam em três EqSF de um município do interior paulista, escolhidas para serem o campo de pesquisa por serem local de estágio do entrevistador ou por se situarem geograficamente próximas.

Entrevistas semidirigidas com questões abertas foram realizadas entre julho de 2008 e maio de 2009. Os temas sobre os quais os participantes foram convidados a refletir ecomentar supostamente permitiram um aprofundamento na expressão dos significados pessoais por eles detidos.
Sete temas foram propostos aos entrevistados: etiologia, diagnóstico, quadro clínico, evolução/prognóstico, aconsel hamento genético/risco de recorrência, vínculo com a USF e necessidades de saúde. 0 áudio das entrevistas foi gravado e reproduzido em arquivos digitais aosquais tiveram acesso os três autores. Foram feitas também transcrições integrais dos diálogos. Os suportes auditivo e escrito dos registros propiciaram a imersão dos pesquisadores no material empírico obtido e nos significados retratados nas entrevistas.

Empreendemos então uma análise dos enunciados identificados, considerados como os significantes das representações sociais objetivadas. As entrevistas foram analisadas uma a uma, de forma independente e individual pelos três pesquisadores. A seguir, foram discutidos os aspectos convergentes e divergentes dessas análises individuais, sendo progressivamente desenvolvida uma categorização desses enunciados.

Observamos que a complexidade dos dados coletados, em razão da proposição detemas abertos e da oportunidade das participantes neles se aprofundarem sem restrição de tempo, ditou a necessidade detentar interpretar as RS sobre vínculo eSD levando em conta também as experiências pessoais e profissionais dos participantes a respeito desses temas.

As principais contribuições teóricas de M oscovici à teoria Durkheiniana das representações coletivas se deram exatamente na valorização do papel criativo e construtivo dos sujeitos sobre as representações sociais. Entendemos que o polo experiencial se constitui como um dos geradores dessas mudanças, fazendo emergir outras significações a partir do processamento cognitivo e emocional de indivíduos que, a partir daí, passam a compartilhá-las explícita ou implicitamente em seus atos.

Assim, foram também consideradas as ideias de Gomese M endonça ${ }^{18}$ e de Turato ${ }^{19}$, que preconizam enfatizar as experiências e vivências humanas nas pesquisas qualitativas na área da saúde. Os primeiros autores destacaram a conveniência de abordar simultaneamente os polos representacional e experiencial das narrativas sobre doenças. Já o segundo autor enfatizou aspectos específicos a serem observados nas pesquisas qualitativas envolvendo profissionais clínicos.

Se as aflições pessoais relacionadas às enfermidades (illness) são dignas de métodos atentos, não menos seriam as aflições dos profissionais dispostos a interagir terapeuticamente com pessoas que consideram portar doenças (diseases). 
Abordagensqualitativasqueprivilegiam esta aproximação entre o clínico (designando quem toma para si al guma responsabilidade direta no cuidado à saúde das pessoas, intervindo) e o paciente/ usuário, ajudam a manter a discussão sobre esses aspectos de angústia do profissional. Assim, do mesmo modo como a vivência de uma enfermidadeoportuniza a expressão de RS sobreesta condição ${ }^{18}$, a vivência clínica relacionada a ajudar a promover saúde e prevenir doenças dá oportunidade à expressão de RS sobre os instrumentos para isto utilizados, sendo o vínculo um deles.

\section{Resultados}

A Q uadro 1 apresenta os dados sociodemográficos individuais de cada entrevistada e a Tabela 1 mostra o perfil sociodemográfico e profissional da amostra como um todo. Como previsto, 0 grupo de participantes foi composto de maneira intencionalmenteheterogênea, dentro das possibilidades práticas de recrutamento encontradas. A totalidade das entrevistas foi feita com pessoas do sexo feminino, a despeito de convites também feitos a profissionais do sexo masculino. A

Quadro 1. Caracterização sociodemográfica individual de cada entrevistada.

1 Feminino; 27; superior completo; enfermeira; branca; solteira; não possui filhos; católica, praticante; há 01 ano na USF; possui contato profissional com indivíduos com SD.

2 Feminino; 37; superior completo; cirurgiã dentista; branca; casada; 01 filho; católica, praticante; há 01 ano e 01 mês na USF; possui contato profissional com indivíduos com SD.

3 Feminino; 23; ensino médio; agente comunitária de saúde; não informou sobre cor da pele; solteira; não possui filhos; católica, praticante; há 03 anos na USF; possui contato profissional com indivíduos com SD.

4 Feminino; 24; superior completo; enfermeira; parda; divorciada; não possui filhos; católica, não praticante; há 20 dias na USF; não possui contato com indivíduos com SD.

5 Feminino; 28; superior completo; médica; não informou sobre cor da pele; solteira; não possui filhos; católica, praticante; há 01 ano na USF; possui contato profissional com indivíduos com SD.

6 Feminino; 30; superior completo; terapeuta ocupacional; branca; casada; 01 filha; católica, não praticante; há 01 ano e 03 meses na USF; possui contato pessoal com indivíduos com SD.

7 Feminino; 22; ensino médio; agente comunitária de saúde; não informou sobre cor da pele; casada; não possui filhos; não possui religião; há 01 ano e 05 meses na USF; possui contato pessoal e profissional com indivíduos com SD.

8 Feminino; 22; ensino médio; agente comunitária de saúde; branca; solteira; não possui filhos; católica, pouco praticante; há 03 anos na USF; possui contato profissional com indivíduos com SD.

9 Feminino; 22; ensino médio; agente comunitária de saúde; parda; solteira; não possui filhos; possui crenças independentes de religião; não praticante; há 03 anos e 03 meses na USF; possui contato profissional com indivíduos com SD.

10 Feminino; 44; superior completo; enfermeira; branca; casada; 04 filhos; católica, praticante; há 01 ano e 06 meses na USF; possui contato profissional com indivíduos com SD.

11 Feminino; 26; superior completo; fonoaudióloga; branca; solteira; não possui filhos; espírita, praticante; há 03 meses na USF; não possui contato com indivíduos com SD.

12 Feminino; 27; superior completo; psicóloga; branca; solteira; não possui filhos; católica, praticante; há 01 ano e 04 meses na USF; não possui contato com indivíduos com SD.

13 Feminino; 28; superior completo; nutricionista; branca; solteira; não possui filhos; católica, praticante; há 01 ano e 06 meses na USF; possui contato profissional com indivíduos com SD.

14 Feminino; 35; superior completo; enfermeira; branca; divorciada; 02 filhos; evangélica, praticante; há 01 ano e 08 meses na USF; possui contato profissional com indivíduos com SD.

15 Feminino; 31; superior completo; enfermeira; branca; casada; não tem filhos; evangélica, praticante; há 02 anos na USF; possui contato profissional com indivíduos com SD.

16 Feminino; 34; superior completo; enfermeira; branca; casada; 01 filho; não possui religião; há 01 ano e 02 meses na USF; possui contato profissional com indivíduos com SD. 
heterogeneidade amostral foi beneficiada pelo programa de residência multiprofissional em funcionamento no município.

O Gráfico 1 mostra como progrediu o processo analítico de tratamento dos dados coletados. O bserve-se que os novos tipos de enunciados tenderam a se concentrar nas primeiras entrevistas, com um "pico" de novos conteúdos já na segunda entrevista e decaindo progressivamente, sobretudo após a sétima. Isso ocorreu a despeito do que consideramos ter sido uma sondagem progressivamente mais qualificada do entrevistador, ao longo das 16 entrevistas.

A Tabela 2 permite visualizar como se deu a distribuição dos 30 tipos de enunciados identificados, já agrupados nas quatro categorias formuladas. Alguns enunciados apareceram uma única vez, e outros apresentaram recorrências frequentes, refletindo possivelmenteos diferentes históricos pessoais e profissionais das entrevistadas.

O Gráfico 1 e a Tabela 2, em conjunto, mostram como a dinâmica de tratamento e análise dos dados levou à interrupção da captação de novos participantes: consideramos ter constado, com certa objetividade, uma saturação teórica dos dados. Isto porque, ao mesmo tempo em que consideramos dispor de el ementos suficientes para atingir os objetivos propostos, verificamos também que não mais surgiam novos tipos deenunciados, em número significativo quejustificasse a continuidade da coleta de dados ${ }^{20-22}$.
Tabela 1. Perfil sociodemográfico e profissional da amostra.

\begin{tabular}{|c|c|c|}
\hline & $\mathrm{N}$ & $\%$ \\
\hline \multicolumn{3}{|l|}{ Sexo } \\
\hline Feminino & 16 & 100 \\
\hline
\end{tabular}

Solteira

Divorciada

50,0

Casada

6,25

Escolaridade

Ensino médio completo $\quad 4 \quad 25,0$

Ensino superior completo $\quad 12 \quad 75,0$

Profissão

Agente Comunitária de Saúde $\quad 4 \quad 25,0$

Cirurgiã Dentista

Enfermeira

Fonoaudióloga

M édica

Nutricionista

Psicóloga

Terapeuta Ocupacional

Religião

$\begin{array}{lll}\text { Católica } & 10 & 62,5\end{array}$

Espírita

Possui crença independente de religião

Evangélica

Não possui

Idade

\section{6,25}

37,5

6,25

6,25

6,25

6,25

6,25

62,5

6,25

6,25

12,5

$\begin{array}{lc}2 & 12,5 \\ 2 \text { a } & 44 \\ \text { média } 28 \text { anos }\end{array}$

anos e 9 meses

(DP \pm 6 meses)

Cor da pele

$\begin{array}{lll}\text { Branca } & 11 & 68,75\end{array}$

$\begin{array}{lll}\text { Parda } & 2 & 12,5\end{array}$

Não informou
18,75

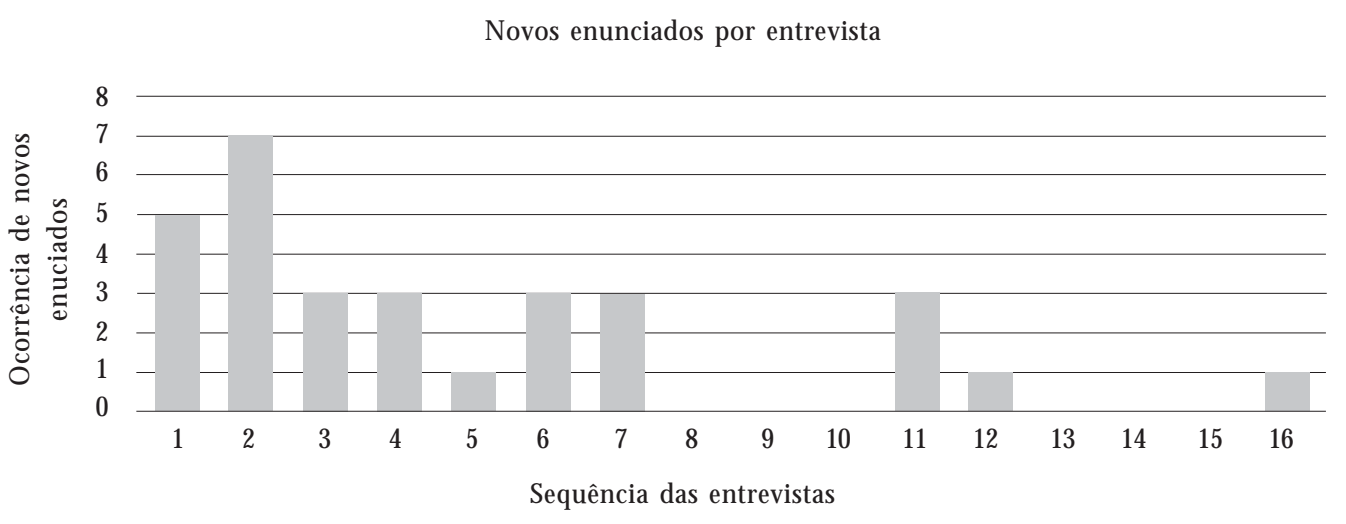

Gráfico 1. Representação gráfica de ocorrências de novos tipos de enunciados ao longo das 16 entrevistas. 
Tabela 2. Novos enunciados e recorrências de enunciados relacionados a "vínculo" entre SD-EqSF,

distribuídas nas quatro categorias formuladas, por ordem de aparecimento ao longo das 16 entrevistas.

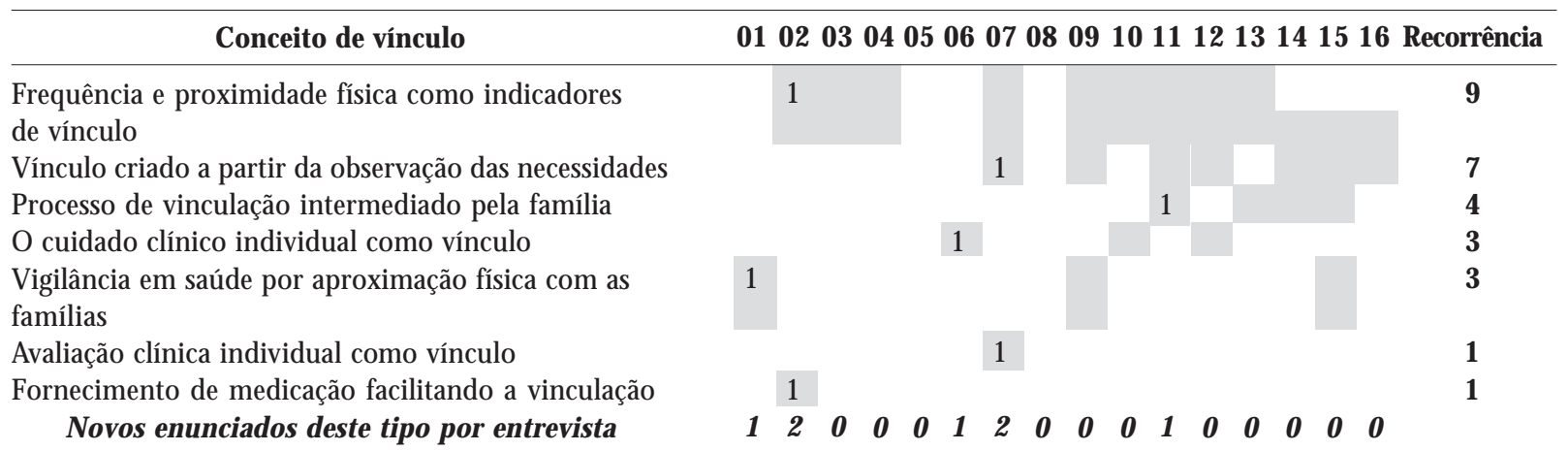

Favorecedores do vínculo

01020304050607080910111213141516 Recorrência

Predisposição afetiva em ajudar

Especificidade da SD não impeditivas de criação de

vínculo

EqSF tem condições para vínculo e seguimento

clínico

Recursos para crianças destinados adultos com SD

Predisposição para cuidado de patologias (não para puericultura)

SD não tem especificidades

1
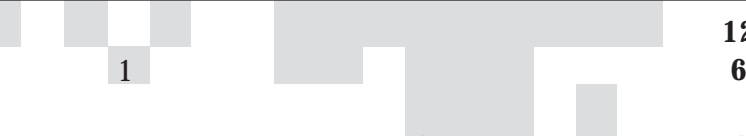

Intersetorialidade favorece 0 vínculo

Predisposição afetiva maximizada por se tratar de criança

Novos enunciados deste tipo por entrevista

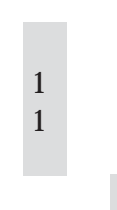

1
12

3

2

1

1

$\begin{array}{llllllllllllllll}1 & 3 & 0 & 2 & 0 & 0 & 1 & 0 & 0 & 0 & 1 & 0 & 0 & 0 & 0 & 0\end{array}$

01020304050607080910111213141516 Recorrência

Ineficiência na formação do vínculo

$\mathrm{N}$ ecessidade de capacitação para então ter vínculo

$\mathrm{N}$ ecessidade de recursos diferenciados para estabelecer

o vínculo

Preconceito social, ao qual a equipe não está imune

Indisposição atitudinal e afetiva

Falta de densidade epidemiológica na APS

Vínculo dificultado pela dificuldade da linguagem

Questionamento da competência da ACS em

começar o vínculo

Novos enunciados deste tipo por entrevista

1

1

1

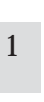

1

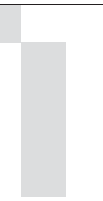

1

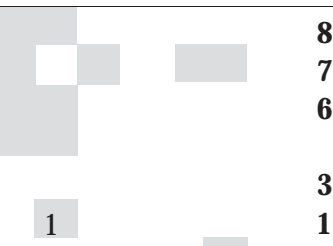

1

$\begin{array}{llllllllllllllll}1 & 1 & 1 & 0 & 0 & 2 & 0 & 0 & 0 & 0 & 0 & 1 & 0 & 0 & 0 & 1\end{array}$

01020304050607080910111213141516 Recorrência

\section{Adscrição falha}

USF suprindo falta de mercado de trabalho e necessidade de socialização

$\mathrm{N}$ ão há programa específico de cuidado

Saúde suplementar responsável pelo cuidado

Grupo como ferramenta para manter o vínculo

Vínculo instável (ora frequenta, ora não frequenta

USF)

USF passiva na gestão do cuidado

Novos enunciados deste tipo por entrevista

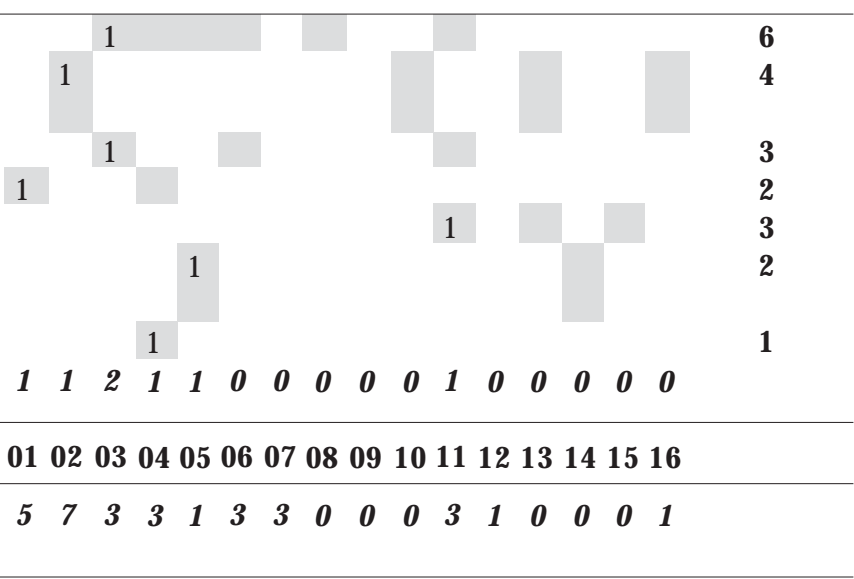




\section{Discussão}

Indícios sobre os modos de produção discursiva dos participantes

As participantes discorreram longamente e aparentemente à vontade sobre o tema vínculo. Sendo este um termo já há algum tempo utilizado no contexto das EqSF, isto pode ter propiciado às profissionais uma sensação de suficiente familiaridade com ele, de modo a considerarem dispor de elementos ideativos para organizarem suas falas.

Como contraponto, ao serem convidadas a falar sobre outros aspectos mais específicos da SD (e quenão são abordados neste artigo), algumas delas pareceram premidas, não se sentindo dominar conhecimentos por elas próprias considerados importantes, revelando certo constrangimento diante de algumas perguntas. De fato, a SD refere-seaum objeto científico eclínico historicamenteausente do contexto daAPS brasileira, de maneira que esta expressão (síndrome de Down) não parece ser vista pelas participantes como um instrumento conceitual que organiza em torno de si conhecimentos na área da saúde, como é função de todo diagnóstico.

Disso parecem resultar dificuldades expressivas sobre aspectos mais técnicos da SD sobre os quais os profissionais de saúde, a priori, deveriam se sentir à vontade. As significações sobre SD dadas pelas ciências médicas (que é o universo reificado aqui considerado ${ }^{14}$ ), com efeito, perpassam dois conjuntos herméticos de habilidades, a clínica e a genética, que exigem processos complexos, estruturados e continuados de capacitação, aos quais as entrevistadas não estariam tendo acesso.

Observe-se adicional menteque os autores da pesquisa, alunos e docentes universitários, podem ter sido percebidos como representantes de um "sistema unificador" correspondente a um "universo reificado" político-ideológico (nas expressões de Moscovici) diante do qual pode ter havido constrangimentos dos participantes.

Entendemos que tais dificuldades podem ter sido parcialmente compensadas por um discurso das participantes que, de modo geral, qualificamos de politicamente correto. A síndrome foi considerada, o mais das vezes, como uma situação normal, sendo assim referida em várias entrevistas. Tais menções à normalidade permitem ao menos duas possibilidades interpretativas: considerar como normal que um profissional da APS se defronte com pacientes com SD (dado o seu caráter de porta de entrada no sistema de saúde) ou, alternativamente, tais menções podem decorrer de uma reatividade emocional defensiva em relação à desordem que esta síndrome genética suscita, fenômeno clínico de difícil compreensão conceitual.

\section{Vínculo como proximidade} no tempo e no espaço

Como esperado, em razão do processamento de uma RS, tal como teorizado pela Psicologia Social, as entrevistadas revelaram uma compreensão de vínculo com uma correspondência parcial ao que a literatura da Saúde tem designado como tal (de maneira pouco explícita, reconheça-se).

Um primeiro núcleo de sentido inferido por nós associa vínculo aos indicadores têmporoespaciais de frequência e proximidade dos usuários em relação às EqSF: quanto maior a frequência do usuário à USF, maior sua vinculação.

0 processo de vigilância em saúde pareceu ser visto como uma decorrência natural desta aproximação física entre U SF-famílias. Não houve, porém, menções sobre como se processaria a vigilância em saúde de casos individuais, ou seja, não foi prevista uma vigilância pautada na atividadeclínica. Diversamente, as entrevistadas relataram propor-se a realizar atividades inespecíficas com os pacientes e suas famílias, como conversar, conhecer a vida familiar, estarem atentas às demandas e explicar-Ihes "o que é" a SD.

\section{Vínculo como cuidado individual}

Um segundo núcleo de sentido conceitual por nósidentificado girou em torno da noção de vínculo como cuidado individual. U ma das entrevistadas, em particular, valorizou o cuidado individual (entendido como eficácia clínica) para a manutenção do vínculo. No entanto, mostrou considerar que tal vínculo se inicia com uma re lação menostécnica e pautada fundamentalmente na boa-vontade do profissional.

Observamos que os dois núcleos de sentido que inferimos existir (vínculo como proximidade têmporo-espacial e vínculo como cuidado individual) se complementam, sendo o primeiro um pano de fundo do segundo. Entretanto, a relação entre ambos pareceu, sobretudo, de outra ordem: de fusão ou de confusão desses sentidos, uma vez que a ênfase no primeiro sentido (proximidade) tenderia a descaracterizar o segundo, ou seja, a proximidade e a frequência de 
comparecimento do usuário à USF estaria no lugar do cuidado clínico. A vinculação não seria fundada no pressuposto contratual tácito de que o usuário das USF encontrará as competências clínicas de que necessita, mas sim queencontrará boa vontade e caminhos institucionais para alcançar tais competências (adscrição, "acolhimentos", encaminhamentos, acessibilidade).

Favorecedores do vínculo

(na ótica das entrevistadas)

Dentre os fatores classificados como favorecedores do vínculo (listados esquematicamente na segunda categoria da Tabela 2), as entrevistadas em geral demonstraram uma atitude de predisposição afetiva em assistir pacientes com SD e suas famílias, predisposição esta maximizada quando se trata de crianças com SD.

As especificidades clínicas daSD não parecem ser vistas como impeditivas de criação de vínculo, havendo no geral a percepção de que a EqSF tem plenas condições para estabelecêlo e mantêlo. Houve também menções a uma falta de especificidades clínicas dos pacientes com SD o que do mesmo modo, sob as óticas das participantes, favoreceria o vínculo, à medida que os pacientes atendidos entrariam nas mesmas rotinas institucionais. Como comentamos anteriormentesobrea produção discursiva deal gunsparticipantes, os pacientes/usuários com SD foram comumente nomeados como normais, necessitando apenas de mais tempo para atingirem um desenvolvimento normal, um aparente recurso retórico politicamente correto que, no entanto, sugere uma lacuna quanto à ideia de equidade do cuidado clínico.

Algumas entrevistadas mostraram-se predispostas ao cuidado de patologias específicas dos pacientes, mas não para a puericultura adequada decrianças com SD, rotina agora esperada naAPS.

Por fim, a inter ação de vários equipamentos sociais, ou seja, a intersetorialidade, foi vista como um facilitador do cuidado clínico e do vínculo.

Ao classificar esses tipos de enunciados como fatores favorecedores, adotamos uma perspectiva êmica, pois correspondem à expressão de intenções das entrevistadas e não necessariamente a uma avaliação objetiva nossa das atuais competências das equipes.

\section{Dificultadores do vínculo}

Dentre os fatores qualificados como dificultadores do vínculo, alguns entraves para estabelecêlo e mantê-lo com pacientes com SD e suas famílias foram mencionados, com destaque para a necessidade de recursos diferenciados e necessidade de capacitação da equipe para proceder ao cuidado. Há, portanto, entre as participantes, visões que se antagonizam com aquela que também foi expressa, deplenas condições para o vínculo e seguimento clínico. Foi também citada a possibilidade da EqSF não estar imune ao preconceito social e rejeitar os pacientes ou, ainda, os médicos (em específico) impingirem-Ihescondutas sem eficácia, em razão de uma indisposição atitudinal ao cuidado deste tipo de paciente.

As dificuldades específicas de comunicação verbal dos pacientes com SD ea falta de conhecimentos e experiência foram também citadas. Foi particularmente questionada a competência das agentes comunitárias de saúde em iniciar o processo de vinculação paciente-família-EqSF.

As entrevistadas mostraram também avaliar o atual momento histórico da relação SD-EqSF como de vinculação ineficaz, ao menos onde trabalham e a falha na adscrição das famílias junto às Unidades seria um indicador disso. A falha adscritícia decorreria também de faltas estruturais (um número inadequado de ACS nas equipes), dificultando a busca ativa por pacientes com SD. Os vínculos atualmente seriam contigenciais, construídos de acordo com as conveniênciasmomentâneas, parecendo haver a percepção de uma falta deestruturação no estabelecimento de relações SD-EqSF.

\section{Características atuais do vínculo SD-EqSF}

M encionou-se não existir hoje programa específico em relação ao cuidado com pacientes com SD eos recursos do sistema suplementar de saúde então se responsabilizariam pelo cuidado.

As USF foram apontadas como tendo um possível papel de distração dos pacientes, suprindo déficits de políticas de social ização e de inserção no mercado de trabalho desta população. 0 "grupo", ou atendimento grupal, foi inespecificamente citado como uma ferramenta para manter 0 vínculo, sem maiores justificativas.

Por fim, os atuais vínculos foram conotados como instáveis: ora devido aos profissionais das EqSF (o programa de residência multiprofissional levando a entra-e-sai de profissionais), ora devido aos pacientes/famílias (que às vezes frequentam e às vezes não a USF). 
Hipóteses explicativas sobre as representações sociais sobre vínculo

Ao que nos parece, um texto de Campos ${ }^{15}$ teria disparado a proposta de empregar nos serviços públicos de saúde o conceito associado ao hoje largamente difundido termo vínculo. Esta proposta baseou-se na noção jurídico-administrativa do contrato vincular que subjaz à prática clínica liberal e comentada anteriormente por Fortes": entre pacientes e profissionais de saúde há um contrato implícito que propicia iniciar ações clínicas e possibilita uma avaliação destas pelos pacientes. Instaura-se, desta maneira, um controle do usuário sobre essas ações que, caso percebidas positivamente, fidelizam a clientela. Desta forma, o vínculo, quando extrapolado para os serviços públicos de saúde, possibilitaria um controle da sociedade sobreos serviços euma longitudinalidade, de fato, do cuidado clínico.

Como estava embutida na proposta de Cam$\operatorname{pos}^{15}$ - difundida em textos de forte penetração entre os profissionais de saúde - parece de fato ter ocorrido um movimento de explosão discursiva sobre vínculo. 0 motivo da escolha da teoria das RS, como modelo interpretativo nesta pesquisa, resi diu exatamente nesta incorporação e transformação dos discursos. M oscovici ${ }^{14}$ salientou, de fato, as possibilidades de uma contínua criação de significados sobre um conceito básico incorporado pelo universo consensual a partir do universo reificado. I sso parece ter ocorrido com o termo-conceito que aqui estudamos. Por caminhos sociais difíceis de serem recuperados integralmente, ao sentido original proposto para utilizar vínculo na APS, teriam sido acrescidos outros.

Pensamos caber a um estudo de representações sociais o levantamento de hipóteses sobre como ocorreram esses desenvolvimentos. Assim, identificamosa possibilidade deque o sentido psicanalítico devínculo possa ter sido influente, dada a ênfase nos aspectos afetivos dos seus sentidos nas entrevistas que realizamos. Até a década de 1980 era hegemônica a utilização determose conceitos psicanalíticos nas reflexões sobre aspectos subjetivos da relação entre pacientes e profissionais/serviços. Embora a teoria das relações objetais, na qual seapoia a noção de vínculo na psicanálise, já estivesse presente nos textos freudianos, particularmenteos desenvolvimentos teóricossulamericanos devem ter tido o poder deinfluenciar essas representações no Brasil, sendo a teoria do vínculo de Pichon-Rivière ${ }^{17}$ marcante para a presente discussão, dado sua explícita e deliberada proposta de empregá-la nas discussões de psiquiatria social e comunitária. Também a teorização de Bowlby ${ }^{16}$ relativa à noção de ligação/apego/ vínculo mãe-bebêpodeigualmenteter influenciado. Hoje, tais sentidos parecem diluídos nas recorrências discursivas sobre vínculo a ponto de não serem reconhecidos no universo consensual a partir das entrevistas que realizamos.

A mesma diluição, a ponto de não reconhecimento, e de maneira provavelmente ainda mais acentuada, teria se passado com a noção jurídico-administrativa de vínculo. Esta noção de uma relação que decorre de um contrato de prestação deserviços mostrou-seinsuspeitada entreos participantes, não mencionada sequer indiretamente.

Entretanto, alguns sentidos denotativos do termo parecem dar os principais subsídios para os participantes falarem sobre como compreendem a relação vincular com pacientes com síndrome de Down. Ao nosso ver, seriam estes os principais pontos de ancoragem das representações sociais identificadas. Particularmente eloquentes seriam os sentidos denotativos de apego e afeição presentes nas falas das entrevistadas, realçando a dimensão afetiva da atuação das participantes em seus trabalhos cotidianos. Compartilhando sentidos denotativos, ateóricos, não houve por parte da amostra, quanto ao vínculo, a contraposição do conhecimento "deles" (dos que detêm os conhecimentos clínicos e genéticos - universo reificado) ao "nosso" (universo consensual).

Note-se que os sentidos de vínculo se aproximam, deste ponto de vista denotativo, aos sentidos subjacentes à clínica ou ao cuidado, quetambém se referem a habilidades dessa dimensão afetiva: zelo, rigor, aplicação, dedicação e atenção. As entrevistadas teriam demonstrado empenho em se inclinarem sobre as necessidades de pessoas em estado de vulnerabilidade.

Porém, esta postura clínica operacionalizarse-ia com a observação das necessidades dos pacientese, tudo indica, tenderia a se dar tão somente assim, passivamente. Outros comportamentos frente a essas necessidades, envolvendo raciocínio clínico e vigilância à saúde individual, não foram enfatizados. Não se entrará em detalhes no presente texto sobre a dimensão cognitiva contida na predisposi ção ao cuidado. Foi caracterizada, porém, por conhecimentos não técnicos, advindos marcadamente da mídia não especializada e de experiências pessoais fora do contexto clínico. N ão foram mencionadas, por exemplo, as medidas antecipatórias de cuidado clínico (prevenção terciária), essenciais para a qualida- 
de do cuidado à SD eque requerem conhecimentos sobrea síndrome; esteve também ausentedos discursos, de um modo geral, a noção das possíveis e previsíveis complicações de saúde a que os indivíduos com SD estão suscetíveis.

H erzlich ${ }^{13}$ enfatizou não ser a finalidade dos estudos de representações sociais a explicação de condutas das pessoas que compartilham certas re presentações, devendo para estetipo de inferência levar-se em consideração também outras variáveis. Não poderíamos, então, fazer induções a este respeito quanto à amostra estudada. Ademais, as particularidades da amostra seriam um impedimento a este tipo de inferência, pois foi composta de profissionais de diferentes formações, incluindo não universitárias, com diversos tipos de competências e que fariam diferenciados tipos de vínculos com seus pacientes. A homogeneidade fundamental ${ }^{23}$ escolhida para estruturar a amostra (trabalhadores nas USF) poderia camuflar as especificidades nela contidas. Sendo assim, não consideramos que aquilo que discutimos representeuma resultanteque retrate de maneira estática o que há de essencial nas re presentações sociais sobre vínculo SD-EqSF. M esmo que a amostra fosse mais homogênea, 0 possível caráter de resultante das representações sociais tenderia a ser, como é típico delas, mais efêmero do que duradouro.

\section{Considerações finais}

A SD é uma condição clínica que é alvo, atualmente, de esforços visando sua desestigmatização na sociedade brasileira, inclusive entre os profissionais de saúde e, embora ainda haja uma baixa densidade destetipo de problema nos serviços de APS, a predisposição afetiva que os componentes da amostra revelaram ter em cuidar sugere, ao nosso ver, que os profissionais já estão suficientemente sensibilizados para a necessidade de interagir com esses pacientes e suas famílias.

Esta interação se fundamentará, com a efetivação da Política Nacional deAtenção Integral em Genética Clínica, a partir de uma mescla específicadesaberestécnico-científicosedesenso comum. No que concerneàs representações dos profissionais sobre o vínculo contratual tácito de prestação deserviços de saúdeaos pacientes com SD na APS - objeto da presente investigação - conside ramos que os saberes expressos pelos participantes se baseiam, sobretudo, nas ideias de habilidades afetivas (afeto dirigido às pessoas acometidas pela síndrome e às suas famílias), de proximida- de física e defrequência de comparecimentos dos pacientes às USF. H abilidades clínicas de outras dimensões (cognitivas, por exemplo) não parecem fundamentar a noção de compromisso ecorresponsabilidade com pacientes com SD (ou de vínculo com eles) entre os participantes.

Caso esta hipótese seja ratificada em estudos avaliativos ou com amostras representativas do conjunto de profissionais das USF brasileiras, a política de saúde pública deveria agora se dirigir para uma efetiva estratégia de educação profissional continuada, de modo a garantir a adequada Iongitudinalidade do cuidado clínico. 0 estabelecimento de linhas de cuidado clínico ediretrizes para as síndromes genéticas mais comuns estaria indicado. A nova estruturação que a Política Nacional de Atenção Integral em Genética Clínica visa implantar parece depender, então, fundamentalmente, destetipo deiniciativa.

M encionamos algumas limitações metodológicas do presente estudo. É plausível considerar a crítica de que a heterogeneidade amostral tenha sido maior do que seria adequado. Porém, a mescla de profissionais com formação superior eformação não superior pode ter sido vantajosa aos nossos propósitos, ao evidenciar de forma mais ampla como se dá a interação EqSF-SD; todos, inclusiveetalvez principalmenteos ACS, estão na interface com a população adscrita. No mesmo sentido, entrevistar profissionais que se especializam em programa de residência multiprofissional em Saúde da Família e Comunidade fez a amostra configurar-se como atípica em relação ao quehoje ocorrenas EqSF brasileiras. Conside ramos, porém, que a vantagem desta estratégia amostral, foi mostrar possíveis ten dências das RS para os próximos anos no contexto da APS.

Há de se considerar também que o processo de saturação teria ocorrido, como é usual nas pesquisas qualitativas, dentro das limitações da técnica de coleta de dados empregada (entrevistas) e dentro das possibilidades de interação cognitiva e afetiva entre entrevistador e participantes; considerando também os limites interpretativos dos autores ${ }^{20-22}$. O utras técnicas de coleta, outros entrevistadores ou outros analistas levariam a resultados diferentes quanto à forma de designar ou interpretar as categorias ou, talvez, a diferentes resultados quanto às próprias categorias. Poderiam levar também a resultados que estivessem além ou aquém dos que chegamos em termos de quantidade de temas, enunciados e significações identificados no corpus. No entanto, 0 atributo de confiabilidade (reliability) nas pesquisas qualitativas não éo que principal- 
mentejustifica empregar estetipo demétodo. De todo modo, procuramos tornar o presente relato transparente quanto ao processo investigativo, com explicações e demonstrações detalhadas das técnicas e procedimentos realizados, o que permitirá aos leitores avaliar a razoabilidade das inferências feitas e, assim, contribuir para maior reprodutibilidade das análises.

\section{Colaboradores}

DG M elo e BJB Fontanella elaboraram o projeto de pesquisa, orientaram a coleta de dados, trabalharam na interpretação dos resultados, na redação e na revisão final do manuscrito. CS Setoue coletou os dados e contribuiu com a interpretação dos resultados.

\section{Agradecimentos}

À Fundação de Amparo à Pesquisa do Estado de São Paulo (FAPESP), pelo apoio financeiro. 


\section{Referências}

1. Brasil. M inistério da Saúde (MS). Gabinete do Ministro. Portaria $n^{\circ} .81$, de 20 de janeiro de 2009. Institui, no âmbito do SUS, a Política Nacional de Atenção Integral em Genética Clínica. Diário Oficial da União 2009; 21 jan. http://dtr2001.saude.gov.br/ sas/PORTARIAS/Port2009/GM/GM - 81.htm (acessado em 27/Jun/2012).

2. Brasil. Ministério da Saúde (MS). Secretaria-Executiva. Núcleo Técnico da Política Nacional de Humanização. Humaniza SUS: Política Nacional de Humanização: a humanização como eixo norteador das práticas de atenção e gestão em todas as instâncias do SUS. Brasília: M S; 2004.

3. Brasil. M inistério da Saúde (M S). Secretaria de Atenção à Saúde. Departamento de Atenção Básica. Política Nacional de Atenção Básica. $4^{a}$ Edição. Brasília: M S: 2007.

4. Fortes PAC. Aspectos ético-jurídicos da responsabilidade civil do médico em prática liberal. Rev Saude Publica 1990; 24(6):518-522.

5. da Cunha EM, Giovanella L. Longitudinalidade/ continuidade do cuidado: identificando dimensões e variáveis para a avaliação da Atenção Primária no contexto do sistema público de saúde brasileiro. Cien Saude Colet 2011; 16 (Supl.1):1029-1042.

6. Weijerman ME, de Winter JP. Clinical practice. The care of children with Down syndrome. Eur J Pediatr 2010; 169(12):1445-1452.

7. Ribeiro M F, Barbosa M A, Porto CC. Paralisia cere bral e síndrome de Down: nível de conhecimento e informação dos pais. Cien Saude Colet 2011; 16(4): 2099-2106.

8. Jensen KM, Taylor LC, Davis M M. Primary care for adults with Down syndrome: adherence to preventive healthcare recommendations. I Intellect Disabil Res 2012; 57(5):409-421.

9. Jensen $\mathrm{KM}$, Davis M M. Health care in adults with Down syndrome: a longitudinal cohort study. J Intellect Disabil Res 2012 [Epub ahead of print].

10. Henderson A, Lynch SA, Wilkinson $S$, Hunter $M$. Adults with Down's syndrome: the prevalence of complications and health care in the community. Br J Gen Pract 2007; 57(534):50-55.

11. Smith DS. Health care management of adults with Down syndrome. Am Fam Physician 2001; 64(6): 1031-1038.

12. Chicoine B, M cGuire D, Hebein S, Gilly D. Use of the community-oriented primary care model for a special-needs population: a clinic for adults with Down syndrome. Am J Public Health 1995; 85(6):869870
13. Herzlich C. A problemática da representação social e sua utilidade no campo da doença. Rev Saude Publica. 2005; 15(Supl.):57-70.

14. Moscovici AS. Representação Social da Psicanálise. Rio de Janeiro: Zahar; 1978.

15. Campos GWS. Considerações sobre a arte e a ciência da mudança: revolução das coisas e reforma das pessoas. O caso da saúde. In: Cecílio LCO organizador. Inventando a mudança na saúde. São Paulo: Hucitec; 1994. p. 29-87.

16. Bowlby J. Apego e perda. 2a Edição. Apego: a natureza do vínculo. Vol. 1. São Paulo: M artins Fontes: 2002. (Original publicado em 1969).

17. Pichon-Rivière E. Teoria do vínculo. São Paulo: M artins Fontes; 1991.

18. Gomes $\mathrm{R}$, M endonça EA. A representação e a experiência da doença: princípio para a pesquisa qualitativa em saúde. In: M inayo M CS, Deslandes SF, organizadores. Caminhos do pensamento: epistemologia e método. Rio de Janeiro: Fiocruz; 2002. p. 109-132.

19. Turato ER. Tratado da metodologia da pesquisa clínico-qualitativa: construção teórico-epistemológica, discussão comparada e aplicação nas áreas de saúde e humanas. 4a Edição. Petrópolis: Vozes; 2010.

20. Fontanella BJB, Luchesi BM, Saidel MGB, Ricas J, Turato ER, M elo DG. Amostragem em pesquisas qualitativas: proposta de procedimentos para constatar saturação teórica. Cad Saude Publica 2011 27(2):388-394.

21. Fontanella BJB, Ricas J, Turato ER. Amostragens por saturação em pesquisas qualitativas: contribuicões teóricas. Cad Saude Publica 2008; 24(1):17-27.

22. Glaser BG, Strauss AL. The Discovery of grounded theory: strategies for qualitative research. New York: Aldine de Gruyter; 1967.

23. M inayo MCS. 0 desafio do conhecimento: pesquisa qualitativa em saúde. 9a Edição. São Paulo: Hucitec; 2006

Artigo apresentado em 10/07/2012

Aprovado em 22/08/2012

Versão final apresentada em 12/09/2012 